\title{
Vitamin D3 and Its Role in the Treatment of Head and Neck Squamous Cell Carcinoma
}

\author{
M. Rita I. Young* and David D. Walker \\ Ralph H. Johnson VA Medical Center, Charleston, \\ Department of Otolaryngology - Head and Neck Surgery \\ Medical University of South Carolina, Charleston
}

USA

\section{Introduction}

Head and neck squamous cell carcinoma (HNSCC) is the $6^{\text {th }}$ most common type of malignancy worldwide, and represents over $6 \%$ of the global cancer burden ${ }^{1}$. Each year, HNSCC accounts for nearly 650,000 new cases of cancer, and over 35,000 deaths worldwide 1,2 . Historically, HNSCC has been a challenging disease to manage, with locally advanced disease often requiring a multidisciplinary approach of surgery, chemotherapy and radiation. However, despite significant advances among the aforementioned fields, the current 5-year survival rate of approximately 50\% has improved very little over the last 30 years 2,3 . This poor improvement in prognosis is a reflection of the unique treatment challenges presented by HNSCC, which include advanced stages at diagnosis, high recurrence rate after surgical removal and second primary tumor development ${ }^{4}$. Moreover, not only are current treatment options often non-curative, but they are associated with significant morbidity, including substantial physical deformity and functional deficits. Together, these challenges underscore the importance of developing novel anti-neoplastic treatment strategies which may improve survival and quality of life among HNSCC patients.

One of the more intriguing novel anti-neoplastic agents is $1 \alpha, 25$-dihydroxyvitamin $\mathrm{D}_{3}$ $\left[\left(1,25(\mathrm{OH})_{2} \mathrm{D}_{3}\right)\right.$, calcitriol], the hormone first identified as an effective treatment for rickets, which has recently garnered wide-spread support as a possible anti-neoplastic agent in a number of different cancer subtypes ${ }^{5}$. Epidemiological observational studies, performed mainly in the United States, have long postulated a correlation between higher latitude residence and overall cancer incidence and mortality. The first such theory was put forth in 1937 by Peller and Stephenson, who together hypothesized that increased sunlight exposure lowered the risk of cancer ${ }^{6}$. Four years later, observational studies defined the relationship further, demonstrating a significant association between geographic latitude and cancer mortality ${ }^{7}$. Since that time, scientists have continued to hypothesize that inadequate serum vitamin D levels at higher latitudes increases one's risk for a number of different cancers including colon, breast, prostate and ovarian cancers ${ }^{8-11}$. Large cohort studies have

${ }^{*}$ Corresponding Author 
confirmed similar findings among HNSCC patients as well. Such studies have not only demonstrated significantly reduced 25-hydroxyvitamin D [25(OH)D] serum levels among HNSCC patients, but also found disease-free survival time to be significantly associated with $25(\mathrm{OH}) \mathrm{D}$ serum levels ${ }^{12}$.

However, a definitive causal relationship is perhaps not as clear as it seems. Though these reports have evoked widespread enthusiasm within the scientific community, such zeal has remained tempered. Most of the data regarding an association between 25(OH)D and cancer is derived from retrospective ecological observational studies. To date, no large-scale randomized control trials have ever been done examining serum $25(\mathrm{OH}) \mathrm{D}$ levels and a primary outcome of cancer. In fact, smaller randomized control studies are extremely limited and yield conflicting results as to the significance of this relationship ${ }^{13}$. There are several prospective studies examining the relationship, but such studies have offered no consensus findings regarding the association 14,15 .

The continued optimism regarding vitamin D's role as an anti-neoplastic agent is sustained, however, by a number of molecular studies which support the biologic feasibility of the theory. In particular, proponents cite the widely expressed vitamin D receptor (VDR), which to date has been found in over 30 different human tissues including lymphocytes, muscle, skin and cancer cells 16,17. Furthermore, the terminal enzyme in the synthesis of active Vitamin D, 1- $\alpha$-hydroxylase, also exhibits widespread expression allowing for synthesis of the hormonally active metabolite in a number of different cell types. Not only is vitamin D capable of ubiquitous synthesis and action, but in vivo studies within both human and animal models suggest that the active metabolite of vitamin D (calcitriol) is capable of eliciting a number of non-calcemic downstream effects. Many of these actions can be considered anti-neoplastic in nature, including anti-inflammatory, proapoptotic, and antiangiogenic properties, the promotion of cell differentiation, and the inhibition of cancercell proliferation.

In this chapter we describe the relevant molecular and biological mechanisms regarding Vitamin D metabolism. We also describe the basic and inherent anti-cancerous properties of vitamin D metabolites, with a specific emphasis on its role in the management of HNSCC.

\section{Overview of vitamin D biological activity}

In 1919, Sir Edward Mellanby conducted a series of elegantly designed experiments on rachitic canines. By placing strict restrictions on both diet and sunlight exposure, he was able to establish a causal relationship between the bone disease rickets and a deficiency of an unidentified trace dietary substance. Mellanby concluded, at that time, that the unknown entity was most likely a previously undescribed fat-soluble vitamin. It was not until 1932, however, that Vitamin D's chemical structure was formally characterized, revealing that Vitamin D was not actually a vitamin, but a steroid hormone. In the late 1960s it was discovered that vitamin $\mathrm{D}$ was actually a precursor of a new steroid hormone, $1,25(\mathrm{OH})_{2} \mathrm{D}_{3}$, produced intrarenally. As both the physical structure and physiologic actions of $1,25(\mathrm{OH})_{2} \mathrm{D}_{3}$ continued to be better characterized, it was soon found to be a critical component of both calcium homeostasis and overall bone health. As research progressed into the $21^{\text {st }}$ century, scientists discovered that the hormone impacted a number of important non-calcemic cell regulatory functions. 
Today, what is commonly referred to as "Vitamin D" is actually a combination of ergocalciferol (vitamin $\mathrm{D}_{2}$ ) and cholicalciferol (vitamin $\mathrm{D}_{3}$ ). Both compounds are readily available in diet form, with vitamin $\mathrm{D}_{2}$ being found in plant products and vitamin $\mathrm{D}_{3}$ found predominately in fatty fish, fish liver oil, and eggs with smaller amounts found in cheese and meat products. In either case, the total amount of either vitamin found within food items is relatively small; thus, many developed countries, including the United States, have turned to fortifying numerous food items, such as milk and juices, with both vitamin $\mathrm{D}_{2}$ and vitamin $D_{3}$. Despite food fortification, diet is not the body's primary means for acquiring vitamin $\mathrm{D}_{3}$ stores. Instead, the majority of the body's cholecalciferol is synthesized in vivo through a photosynthic process occurring in the epidermal layer of sun-exposed skin. Upon exposure to ultraviolet radiation, the epidermis is capable of transforming a cholesterol derivative (7-dehydrocholesterol) into vitamin $\mathrm{D}_{3}$ (cholecalciferol). The catalysis, however, is not uniform among all populations and is subject to significant and intense variations based on skin pigmentation, sunscreen use, age, gender and even obesity 18 .

After synthesis, cholecalciferol enters the blood stream and is transported to the liver. There it undergoes intra-hepatic hydroxylation at the 25 position to create 25 -hydroxyvitamin $\mathrm{D}_{3}$ $\left[25(\mathrm{OH}) \mathrm{D}_{3}\right.$ or calcidiol]. $25(\mathrm{OH}) \mathrm{D}_{3}$ is the circulating form of the hormone within the plasma as well as the most accurate biomarker of overall Vitamin D3 status ${ }^{19} .25(\mathrm{OH}) \mathrm{D}_{3}$ is next catalyzed into one of two metabolites: the biologically inert 24,25-dihydroxyvitamin D3 $\left[24,25(\mathrm{OH})_{2} \mathrm{D}_{3}\right]$ or the biologically active metabolite 1,25-dihydroxyvitamin D3 $\left[1,25(\mathrm{OH})_{2} \mathrm{D}_{3}\right]$. Exactly which metabolite is created depends entirely on what enzyme is expressed within the local tissue. If the tissue expresses 24-hydroxylase (also known as CYP24A1), then $25(\mathrm{OH}) \mathrm{D}_{3}$ is modified to become $24,25(\mathrm{OH})_{2} \mathrm{D}_{3}$. This particular metabolite has poor affinity and avidity toward the VDR and is considered the first step in vitamin D decomposition. Alternatively, if the tissue expresses 1- $\alpha$ hydroxylase (also known as CYP27B1), the biologically active metabolite $1,25(\mathrm{OH})_{2} \mathrm{D}_{3}$ is formed. This particular metabolite is most well known for its regulation of calcium homeostasis and is the metabolite capable of exerting anti-neoplastic effects on cancer cells.

\section{Vitamin D mechanism of action}

The majority of Vitamin D's hormonal action involves direct interaction with a single VDR. An intranuclear regulator of gene transcription, the VDR is a member of the class II steroid hormone receptors and is closely related to the retinoic acid and thyroid hormone receptors 17. The human receptor is located on chromosome 12q12q14 and consists of nine exons. Fully transcribed, the receptor is a 427-amino acid peptide with relatively simple binding configuration consisting of a DNA-binding domain termed the C-domain, a ligand-binding domain called the E-domain and an activating domain called the F-domain. The receptor acts by interacting with portions of DNA called vitamin D-responsive elements (VDREs). Located in the promoter region of target genes, VDRES are commonly found within 1 kilobase from the gene start sequence. Such areas are composed of hexanucleotide repeats separated by 3 nonspecified nucleotide bases (for example CGACTA-NNN-CGACTA where $\mathrm{N}$ represents any nucleotide).

Once $1,25(\mathrm{OH})_{2} \mathrm{D}_{3}$ is transported into the cell, it enters the nucleus where it is capable of binding to VDR. After binding, the $1,25(\mathrm{OH})_{2} \mathrm{D}_{3}-\mathrm{VDR}$ complex synergistically 
heterodimierizes with retinoid-X receptor (RXR). The $1,25(\mathrm{OH})_{2} \mathrm{D}_{3}-\mathrm{VDR}-\mathrm{RXR}$ complex then binds specifically to a VDRE sequence complex, with the VDR occupying the $3^{\prime}$ region and the RXR positioned at the $5^{\prime}$ end. Conformational changes which occur after $1,25(\mathrm{OH})_{2} \mathrm{D}_{3}$ binding results in the release of coreppressors and the simultaneous exposure of binding sites for transcriptional coactivators. VDR coactivators are then capable of binding the complex, which results in the acetylation and subsequent release of histones from the DNA strand. Without histones in place, the appropriate transcription factors are capable of binding to the naked DNA strand and transcription of the target gene is able to initiate.

Certain variables that construct this transcriptional machinery apparatus may have a direct role within the formation of cancer. Recent resequencing of VDR gene identified 194 singlenucleotide polymorphisms (SNPs). It has been hypothesized that VDR SNPs themselves may have a direct impact on formation and prognosis of certain types of cancer, including HNSCC. The two most widely investigated receptors regarding their impact and role within cancer include a FokI restriction fragment-length polymorphism (RFLP) in exon 2 and an adjacent TaqI RFLP in exon 9. These two polymoprhisms were recently investigated with respect to their association with HNSCC incidence. Such studies yielded mixed results. Findings from one study demonstrated that the heterozygous genotype of Taq I (Tt) polymorphism may be associated with an increased susceptibility to HNSCC 20 . In a separate study, however, both homozygous variant genotypes, TaqI (tt) and FokI (ff), were associated with a reduced risk of HNSCC as compared to the more common TaqI (TT) and FokI (FF) genotypes. Thus, it remains uncertain as to whether or not specific VDR SPNs provide a protective or deleterious effect regarding HNSCC risk 21. However, demonstrations of both increased and decreased HNSCC risk warrant continued research into how VDR SNPs may not only impact cancer incidence, but also mortality and treatment response.

\subsection{Biological plausibility within cancer}

The general biologic characteristics and mechanisms of action detailed above presented two main molecular hurdles for scientists considering $1,25(\mathrm{OH})_{2} \mathrm{D}_{3}$ as a plausible anti-neoplastic agent. First, there was the seemingly restricted localization of 1- $\alpha$ hydroxylase. The enzyme responsible for converting vitamin $\mathrm{D}$ into its active form is highly expressed in renal proximal tubules and was once thought to be solely expressed intra-renally However, it is now known that many non-renal cells, including bone, placenta, prostate, keratinocytes, macrophages, T-lymphocytes, dendritic cells and several cancer cells all express the converting enzyme capable of producing the hormonally active metabolite $1,25(\mathrm{OH})_{2} \mathrm{D}_{3}{ }^{22}$. This particular formation of Vitamin D contains a high affinity for the VDR and is capable of eliciting an anti-neoplastic response. It is this formation with which we concern ourselves for the remainder of the discussion.

The second major impasse was the restrictive localization of VDR to skeletal tissues. However, since VDRs were first discovered their localization has been confirmed on a variety of tissues. With respects to SCC, it has been demonstrated that not only do human cancer cell lines (SCL-1, SCL-2 ) exhibit VDR expression, but in fact they express the receptor in higher amounts than normal human skin cell lines ${ }^{23}$. The discovery of extra-renally expressed 1- $\alpha$ hydroxylase and extra-skeletally expressed VDR was paramount in vitamin D's acceptance as a possible anticancer agent. Such findings sustained the molecular 
integrity of the theory, paving the way for the initiation of many phase I and phase II clinical trials.

\section{Vitamin D and cancer}

Thus far, $1,25(\mathrm{OH})_{2} \mathrm{D}_{3}$ has been presented as a secosteroid whose fundamental intra-nuclear action is critical for appropriate regulation of calcium homeostasis and proper bone mineralization. Vitamin D, however, has other non-calcemic regulatory functions, including many which make it an intriguing anti-neoplastic agent. Four separate cellular functions tend to be compromised in order for cancer to thrive within a normal host environment: 1) aberrant regulation of differentiation, 2) dysregulated cellular proliferation, 3) newly acquired ability permitting invasion and metastasis, 4) dysregulated cell destruction of altered self-cells. Numerous published reports have demonstrated that $1,25(\mathrm{OH})_{2} \mathrm{D}_{3}$ is capable of restoring or repairing each of the aforementioned hallmarks of carcinogenesis. It does so in a number of ways, including inhibition of cellular proliferation, disruption and inhibition of angiogenesis, promoting apoptosis, and improving tumor immunosurveillence.

\subsection{Cellular proliferation and differentiation}

The processes of cellular proliferation and differentiation are intimately intertwined, and the aberrant regulation of each is critically important to the prosperity of growing cancer cells. The normal cell grows along a continuum of cellular differentiation. As a cell proceeds toward terminal differentiation, its ability to divide and proliferate is decreased. This feature is exploited and utilized by many newer anti-neoplastic agents, including $1,25(\mathrm{OH})_{2} \mathrm{D}_{3}$. A promising feature of $1,25(\mathrm{OH})_{2} \mathrm{D}_{3}$ is its ability to manipulate the cell's state of differentiation. In vitro studies in human cell lines demonstrated that $1,25(\mathrm{OH})_{2} \mathrm{D}_{3}$ is capable of reducing cell proliferation by inducing cell cycle arrest in G0/G1 phase while simultaneously promoting cellular differentiation 24,25 .

These results were replicated within murine SCC cell lines which showed that administration of $1,25(\mathrm{OH})_{2} \mathrm{D}_{3}$ to cells induces $\mathrm{G} 0 / \mathrm{G} 1$ cell-cycle arrest via the transcriptional activation of CDKN1B and subsequent dephosphorylation of pRB 26. The study demonstrated that in both in vivo and in vitro studies, the increases seen in CDKN1B were the result of downregulated p21 activity, a potent CDK inhibitor ${ }^{26}$. Human SCC cell lines that positively express VDR showed a potent decrease in cellular proliferation when exposed to $1,25(\mathrm{OH})_{2} \mathrm{D}_{3}$ and its analogues ${ }^{27}$. Vitamin $\mathrm{D}^{\prime}$ 's ability to force cells into differentiation may be of critical importance, as such actions can aid in the inhibition of tumor cell proliferation 28 .

\subsection{Angiogenesis}

Cancer cells will often acquire the ability to escape the confines of the original tumor nidus. The tumor cell often relies heavily on its angiogenic properties to spread. In theory, limiting the tumor's ability to aberrantly generate rogue blood supplies may limit its ability to thrive and metastasize, offering a potential avenue to achievement of loco-regional control. Several studies have demonstrated that $1,25(\mathrm{OH})_{2} \mathrm{D}_{3}$ contains potent antiangiogenic properties capable of reducing the invasiveness of cancer cells. In vitro studies demonstrated that 
$1,25(\mathrm{OH})_{2} \mathrm{D}_{3}$ and its analogs directly inhibit tumor-derived endothelial cell proliferation in addition to disrupting angiogenic signaling in cancer cells 29.

Within HNSCC cell-lines, treatment with $1,25(\mathrm{OH})_{2} \mathrm{D}_{3}$ resulted in a significantly lower production of pro-angiogenic cytokines, VEGF and PDGF 27. Meanwhile, the proinflammatory and proangiogenic cytokine, IL-8, exhibits no change after administration of $1,25(\mathrm{OH})_{2} \mathrm{D}_{3}$ 27. The finding of decreasing concentrations of VEGF has prompted considerable interest, as it has not only been cited as a marker for tumor metastasis, but also used as a prognostic factor in HNSCC patients 30,31 .

\subsection{Apoptosis}

Apart from its actions on the cell cycle, $1,25(\mathrm{OH})_{2} \mathrm{D}_{3}$ can also suppress cancer growth via induction of apoptosis ${ }^{32-34}$. Results carried out on human HNSCC cell lines demonstrated that exposure to $1,25(\mathrm{OH})_{2} \mathrm{D}_{3}$ results in the downregulaion of several anti-apoptotic genes. In particular, $1,25(\mathrm{OH})_{2} \mathrm{D}_{3}$ represses the expression of the anti-apoptotic, pro-survival gene BCL-2 while simultaneously increasing pro-apoptotic gene products of BAX and BAK ${ }^{35}$. Studies completed on mouse SCC tumor cells with $1,25(\mathrm{OH})_{2} \mathrm{D}_{3}$ revealed a form of caspase-dependent apoptosis involving the growth-promoting/pro-survival signaling molecule, mitogen-activated protein kinase kinase (MEK) ${ }^{36}$. The study was able to demonstrate that exposure to $1,25(\mathrm{OH})_{2} \mathrm{D}_{3}$ resulted in increased VDR expression and concomitant cleavage of the pro-survival signaling molecule MEK via a caspasedependent manner.

\subsection{Immune escape}

Key to the survival of cancer cells is the evasion of destruction, a critically fundamental step of which is the ability to evade the immune system. HNSCC, like all cancers, is capable of evading the host's immune system via a number of different mechanisms. Cancer can evade antigenic recognition via tissue sequestration, improper lymphocytic homing due to improper expression of adhesion molecules, and antigenic shedding and modulation. In certain instances, however, antigenic recognition remains intact, despite a poor immune response. In such cases, cancers continue to thrive by releasing immunosuppressive cytokine, downregulating MHC I complex, or instilling dysregulated or improper costimulation

Numerous studies performed on HNSCC patients have investigated the effects of $1,25(\mathrm{OH})_{2} \mathrm{D}_{3}$ on the immune profile of patients. Within the past 10 years, it has been shown that not only do monocytes, B-cells, and T-cells express VDR, but also contain the enzyme 1$\alpha$-hydroxylase capable of converting $25(\mathrm{OH}) \mathrm{D}_{3}$ into $1,25(\mathrm{OH})_{2} \mathrm{D}_{3}{ }^{37}$. Such findings confirmed long-standing speculation that vitamin $\mathrm{D}$ is critical for the appropriate management and integrity of the immune system. Numerous studies have since attempted to understand exactly how vitamin D modulates the host immune profile.

HNSCC itself is associated with profound immunosuppression ${ }^{38}$. This is in part due to tissue infiltration by immunosuppressive immature progenitor cells with surface marker CD34 39,40 . In one study, HNSCC patients treated with $1,25(\mathrm{OH})_{2} \mathrm{D}_{3}$ exhibited decreased levels of intratumoral $\mathrm{CD} 34^{+}$cell populations and diminished the preexisting profound 
immunoinhibitory effect of the cancer. Such findings suggest that $1,25(\mathrm{OH})_{2} \mathrm{D}_{3}$ may be helpful in overcoming the profound immunosuppression associated with HNSCC ${ }^{41}$.

Tissues of HNSCC patients who received treatment with $1,25(\mathrm{OH})_{2} \mathrm{D}_{3}$ contained increased levels of $\mathrm{CD}^{+}$cells and, more significantly, $\mathrm{CD} 8{ }^{+} \mathrm{T}$ cells. Such findings indicate an increased infiltration of immune effector cells into the tumor microenvironment. Also prominent was an increase in cells expressing the lymphoid activation marker CD69, which represent mainly $\mathrm{T}$ cells and monocytes. The same study showed that HNSCC patients who received $1,25(\mathrm{OH})_{2} \mathrm{D}_{3}$ prior to treatment had a lengthier time to tumor recurrence compared with patients who were not treated before surgery. The treatment arm exhibited a median time to recurrence that was almost 3.5-fold longer than control patients who were untreated before surgery ${ }^{42}$. These findings are complemented by separate studies suggesting that treatment with $1,25(\mathrm{OH})_{2} \mathrm{D}_{3}$ may be an appropriate method of restarting the immune system ${ }^{43}$.

\section{Future clinical considerations}

One of the most discussed aspects regarding the implementation of vitamin D as an anticancer medication is dosing regimen. The Institute of Medicine recently addressed vitamin $\mathrm{D}$ dosing regimens in its newly published Dietary Referenced Intakes for Vitamin D. Their review of the literature yielded the suggested dietary intake of $600 \mathrm{IU}$ per day for persons 1 to 70 years of age and $800 \mathrm{IU}$ per day for persons over 70 . Such intakes corresponded to serum $25(\mathrm{OH}) \mathrm{D}$ levels of at least $20 \mathrm{ng}$ per milliliter (50 nmol per liter) with recommended daily ingestion not to exceed 4000 IU per day ${ }^{44}$. The same review concluded that the prevalence of vitamin D deficiency in North America, which previously published reports had suggested to be as high as $54 \%$ in some populations, has been drastically overestimated 45. The authors concluded that the vast majority of North American individuals have serum $25(\mathrm{OH}) \mathrm{D}$ concentrations above $20 \mathrm{ng}$ per milliliter, which is adequate for bone health in at least $97.5 \%$ of the population

Another area of debate is the concept of vitamin D screening as a predictor for cancer incidence. Since its inception, many have taken disagreed with such practices. One of the main areas of contention rests in the number of confounding variables associated with low serum $25(\mathrm{OH}) \mathrm{D}$ levels. These variables, which include obesity, lack of physical activity, and poor diet or supplementation practices, have the ability to impact cancer risk. Critics also cite reverse-causation bias, noting that in certain individuals poor health reduces one's ability to participate in outdoor activities, resulting in lower vitamin D levels.

\section{Conclusion and future perspective}

It is the opinion of the authors that the role of $1,25(\mathrm{OH})_{2} \mathrm{D}_{3}$ as an anti-cancer agent warrants continued clinical and laboratory exploration. Further investigation into the relationship calls for randomized control trials of vitamin $\mathrm{D}$ for cancer prevention. As noted by the recently published IRAC review, observational studies themselves are unlikely to "disentangle the complex relationships between vitamin D and known cancer risk factors 46." Such reports, however, have paved the way for numerous ongoing phase I and II clinical trials which should begin to elucidate what role, if any, $1,25(\mathrm{OH})_{2} \mathrm{D}_{3}$ may play in the treatment of HNSCC. 


\section{References}

[1] Vokes EE, Weichselbaum RR, Lippman SM, Hong WK. Head and Neck Cancer. New England Journal of Medicine 1993;328:184-94.

[2] Parkin DM, Bray F, Ferlay J, Pisani P. Global Cancer Statistics, 2002. CA Cancer J Clin 2005;55:74-108.

[3] Leemans C, Tiwari R, Nauta J, van der Waal I, Snow G. Recurrence at the primary site in head and neck cancer and the significance of neck lymph node metastases as a prognostic factor. Cancer 1994;73:187-90.

[4] Jones A, Morar P, Phillips D, Field J, Husband D, Helliwell T. Second primary tumors in patients with head and neck squamous cell carcinoma. Cancer 1995;75:1343-53.

[5] Mellanby E. An experimental investigation on rickets. 1919. Nutrition 1989;5:81-7.

[6] Peller S. Skin Irritation and Cancer in the U.S. Navy. American Journal of the Medical Sciences 1937;194:326-33.

[7] Apperly FL. The Relation of Solar Radiation to Cancer Mortality in North America. Cancer Research 1941;1:191-5.

[8] Garland CF, Garland FC. Do Sunlight and Vitamin D Reduce the Likelihood of Colon Cancer? International Journal of Epidemiology 1980;9:227-31.

[9] Garland F, Garland C, Gorham E, Young J. Geographic variation in breast cancer mortality in the United States: a hypothesis involving exposure to solar radiation. Preventive Medicine 1990;19:614-22.

[10] Lefkowitz E, Garland CF. Sunlight, Vitamin D, and Ovarian Cancer Mortality Rates in US Women. International Journal of Epidemiology 1994;23:1133-6.

[11] Hanchette C, Schwartz G. Geographic patterns of prostate cancer mortality. Evidence for a protective effect of ultraviolet radiation. Cancer 1992;70:2861-9.

[12] Gugatschka M, Kiesler K, Obermayer-Pietsch B, Groselj-Strele A, Griesbacher A, Friedrich G. Vitamin D status is associated with disease-free survival and overall survival time in patients with squamous cell carcinoma of the upper aerodigestive tract. European Archives of Oto-Rhino-Laryngology 2011:1-4.

[13] Manson JE, Mayne ST, Clinton SK. Vitamin D and Prevention of Cancer , ̈̈̂̂̀ Ready for Prime Time? New England Journal of Medicine 2011;364:1385-7.

[14] Freedman DM, Looker AC, Chang S-C, Graubard BI. Prospective Study of Serum Vitamin D and Cancer Mortality in the United States. Journal of the National Cancer Institute 2007;99:1594-602.

[15] Pilz S, Dobnig H, Winklhofer-Roob B, et al. Low Serum Levels of 25-Hydroxyvitamin D Predict Fatal Cancer in Patients Referred to Coronary Angiography. Cancer Epidemiology Biomarkers \& Prevention 2008;17:1228-33.

[16] Norman AW. Vitamin D Receptor: New Assignments for an Already Busy Receptor. Endocrinology 2006;147:5542-8.

[17] Jones G, Strugnell SA, DeLuca HF. Current Understanding of the Molecular Actions of Vitamin D. Physiological Reviews 1998;78:1193-231.

[18] Binkley N, Novotny R, Krueger D, et al. Low Vitamin D Status despite Abundant Sun Exposure. Journal of Clinical Endocrinology \& Metabolism 2007;92:2130-5.

[19] Hollis BW, Wagner CL, Drezner MK, Binkley NC. Circulating vitamin D3 and 25hydroxyvitamin D in humans: An important tool to define adequate nutritional vitamin D status. The Journal of Steroid Biochemistry and Molecular Biology 2007;103:631-4. 
[20] Bektas-Kayhan K, Unur M, Yaylim-Eraltan I, et al. Association of vitamin D receptor Taq I polymorphism and susceptibility to oral squamous cell carcinoma. In Vivo 2010;24:755-9.

[21] Liu Z, Calderon JI, Zhang Z, Sturgis EM, Spitz MR, Wei Q. Polymorphisms of vitamin $D$ receptor gene protect against the risk of head and neck cancer. Pharmacogenetics and Genomics 2005;15:159-65.

[22] Zehnder D, Bland R, Williams MC, et al. Extrarenal Expression of 25-Hydroxyvitamin D3-Hydroxylase. Journal of Clinical Endocrinology \& Metabolism 2001;86:888-94.

[23] Reichrath J, Rafi L, Rech M, et al. Analysis of the vitamin D system in cutaneous squamous cell carcinomas. Journal of Cutaneous Pathology 2004;31:224-31.

[24] Nagpal S, Na S, Rathnachalam R. Noncalcemic Actions of Vitamin D Receptor Ligands. Endocrine Reviews 2005;26:662-87.

[25] DeLuca H. The vitamin D story: a collaborative effort of basic science and clinical medicine. The FASEB Journal 1988;2:224-36.

[26] Hershberger PA, Modzelewski RA, Shurin ZR, Rueger RM, Trump DL, Johnson CS. 1,25-Dihydroxycholecalciferol (1,25-D3) Inhibits the Growth of Squamous Cell Carcinoma and Down-Modulates p21Waf1/Cip1 in Vitro and in Vivo. Cancer Research 1999;59:2644-9.

[27] Satake K, Takagi E, Ishii A, et al. Anti-tumor effect of vitamin A and D on head and neck squamous cell carcinoma. Auris, nasus, larynx 2003;30:403-12.

[28] Stein J, van Wijnen A, Lian J, Stein G. Control of cell cycle regulated histone genes during proliferation and differentiation. International Journal of Obesity and Related Metabolic Disorders 1996;20:S84-90.

[29] Bernardi RJ, Johnson CS, Modzelewski RA, Trump DL. Antiproliferative Effects of 1,25Dihydroxyvitamin D3 and Vitamin D Analogs on Tumor-Derived Endothelial Cells. Endocrinology 2002;143:2508-14.

[30] Sauter ER, Nesbit M, Watson JC, Klein-Szanto A, Litwin S, Herlyn M. Vascular Endothelial Growth Factor Is a Marker of Tumor Invasion and Metastasis in Squamous Cell Carcinomas of the Head and Neck. Clinical Cancer Research 1999;5:775-82.

[31] Salven P, Heikkila P, Anttonen A, Kajanti M, Joensuu H. Vascular endothelial growth factor in squamous cell head and neck carcinoma: expression and prognostic significance. Modern pathology : an official journal of the United States and Canadian Academy of Pathology, Inc 1997;10:1128-33.

[32] Simboli-Campbell M, Narvaez CJ, Tenniswood M, Welsh J. 1,25-Dihydroxyvitamin D3 induces morphological and biochemical markers of apoptosis in MCF-7 breast cancer cells. The Journal of Steroid Biochemistry and Molecular Biology 1996;58:367-76.

[33] Benassi L, Ottani D, Fantini F, et al. 1,25-dihydroxyvitamin D3, transforming growth factor beta1, calcium, and ultraviolet B radiation induce apoptosis in cultured human keratinocytes. The Journal of Investigative Dermatology 1997;109:276-82.

[34] Vandewalle B, Wattez N, Lefebvre J. Effects of vitamin D3 derivatives on growth, differentiation and apoptosis in tumoral colonic HT 29 cells: possible implication of intracellular calcium. Cancer Letters 1995;97:99-106.

[35] Ylikomi T, Laaski I, Lou Y, et al. Antiproliferative action of vitamin D. Vitamins and Hormones 2002;64:357-406. 
[36] McGuire TF, Trump DL, Johnson CS. Vitamin D3-induced Apoptosis of Murine Squamous Cell Carcinoma Cells. Journal of Biological Chemistry 2001;276:26365-73.

[37] van Etten E, Decallonne B, Verlinden L, Verstuyf A, Bouillon R, Mathieu C. Analogs of 1a,25-dihydroxyvitamin D3 as pluripotent immunomodulators. Journal of Cellular Biochemistry 2003;88:223-6.

[38] Heimdal J, Aarstad H, Klemensten B, Olofsson J. Peripheral blood mononuclear cell (PBMC) responsiveness in patients with head and neck cancer in relation to tumour stage and prognosis. Acta oto-laryngologica 1999;119:281-4.

[39] Pandit R, Lathers D, Beal N, Garrity T, Young M. CD34+ immune suppressive cells in the peripheral blood of patients with head and neck cancer. Annals of otology, rhinology, and laryngology 2000;109:749-54.

[40] Young MRI, Lathers DMR. Myeloid progenitor cells mediate immune suppression in patients with head and neck cancers. International Journal of Immunopharmacology 1999;21:241-52.

[41] Kulbersh J, Day T, Gillespie M, Young M. 2009. Otolaryngology Head and Neck Surgery 2009;140:235-40.

[42] Walsh JE, Clark A-M, Day TA, Gillespie MB, Young MRI. Use of [alpha],25Dihydroxyvitamin D3 treatment to stimulate immune infiltration into head and neck squamous cell carcinoma. Human Immunology 2010;71:659-65.

[43] Fleet JC. Molecular actions of vitamin D contributing to cancer prevention. Molecular Aspects of Medicine 2008;29:388-96.

[44] IOM (Institue of Medicine). 2011. Dietary Reference Intakes for Calcium and Vitamin D. Washington, DC: The National Academies Press.

[45] Bodnar LM, Simhan HN, Powers RW, Frank MP, Cooperstein E, Roberts JM. High Prevalence of Vitamin D Insufficiency in Black and White Pregnant Women Residing in the Northern United States and Their Neonates. The Journal of Nutrition 2007;137:447-52.

[46] IARC. Vitamin D and Cancer. IARC Working Group Reports Vol. 5, International Agency for research on Cancer. Lyon 25 November 2008. 


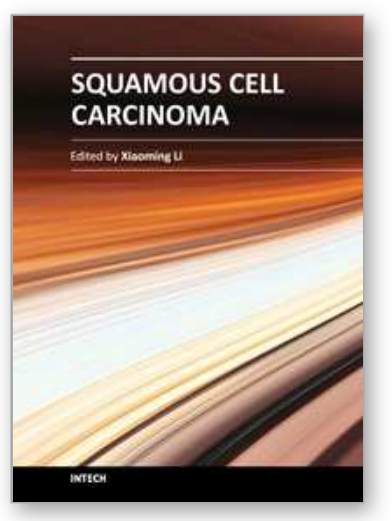

\author{
Squamous Cell Carcinoma
}

Edited by Prof. Xiaoming Li

ISBN 978-953-51-0024-9

Hard cover, 302 pages

Publisher InTech

Published online 03, February, 2012

Published in print edition February, 2012

This book points to some new areas for investigation on squamous cell carcinoma (SCC). Firstly, the features and management of some specific SCC is discussed to give the readers the general principles in dealing with these uncommon and sophisticated conditions. Some new concepts in adjuvant therapy including neoadjuvant therapy and gold nanoparticle-based photo dynamic therapy are introduced. Secondly, a detailed discussion of molecular aspects of tumor invasion and progression in SCC is provided with the emphasis on the roles of some important factors. The role of tumor microenvironment in head and neck SCC is specifically discussed. Thirdly, the roles of cancer stem cells (CSC) in cancer therapy of SCC are described. Molecular mechanisms involving therapeutic resistance and new therapeutic strategies targeting CSC are discussed in detail. Finally, other aspects concerning SCC are included, which involve the assessment, genetic manipulation and its possible clinical implications for the treatment of SCC.

\title{
How to reference
}

In order to correctly reference this scholarly work, feel free to copy and paste the following:

M. Rita I. Young and David D. Walker (2012). Vitamin D3 and Its Role in the Treatment of Head and Neck Squamous Cell Carcinoma, Squamous Cell Carcinoma, Prof. Xiaoming Li (Ed.), ISBN: 978-953-51-0024-9, InTech, Available from: http://www.intechopen.com/books/squamous-cell-carcinoma/vitamin-d3-and-its-role-inthe-treatment-of-head-and-neck-squamous-cell-carcinoma

\section{INTECH}

open science | open minds

\author{
InTech Europe \\ University Campus STeP Ri \\ Slavka Krautzeka 83/A \\ 51000 Rijeka, Croatia \\ Phone: +385 (51) 770447 \\ Fax: +385 (51) 686166 \\ www.intechopen.com
}

\author{
InTech China \\ Unit 405, Office Block, Hotel Equatorial Shanghai \\ No.65, Yan An Road (West), Shanghai, 200040, China \\ 中国上海市延安西路65号上海国际贵都大饭店办公楼 405 单元 \\ Phone: +86-21-62489820 \\ Fax: $+86-21-62489821$
}


(C) 2012 The Author(s). Licensee IntechOpen. This is an open access article distributed under the terms of the Creative Commons Attribution 3.0 License, which permits unrestricted use, distribution, and reproduction in any medium, provided the original work is properly cited. 